OPEN ACCESS

Edited by:

Akio Adachi,

Kansai Medical University, Japan

Reviewed by:

Hiroshi Nyunoya,

Waseda University, Japan

Bernard Epel,

Tel Aviv University, Israel

Richard S. Nelson,

Oklahoma State University,

United States

*Correspondence:

Yuri L. Dorokhov

dorokhov@belozersky.msu.ru

Specialty section:

This article was submitted to

Virology, a section of the journal

Frontiers in Plant Science

Received: 18 April 2020

Accepted: 10 June 2020

Published: 24 June 2020

Citation:

Sheshukova EV, Ershova NM Kamarova KA, Dorokhov YL and Komarova TV (2020) The Tobamoviral Movement Protein: A "Conditioner" to

Create a Favorable Environment for Intercellular Spread of Infection.

Front. Plant Sci. 11:959.

doi: 10.3389/fpls.2020.00959

\section{The Tobamoviral Movement Protein: A "Conditioner" to Create a Favorable Environment for Intercellular Spread of Infection}

\author{
Ekaterina V. Sheshukova ${ }^{1}$, Natalia M. Ershova ${ }^{1}$, Kamila A. Kamarova ${ }^{1,2}$, \\ Yuri L. Dorokhov ${ }^{1,3^{*}}$ and Tatiana V. Komarova ${ }^{1,3}$
}

1 Vavilov Institute of General Genetics, Russian Academy of Sciences, Moscow, Russia, ${ }^{2}$ Faculty of Bioengineering and Bioinformatics, Lomonosov Moscow State University, Moscow, Russia, ${ }^{3}$ Belozersky Institute of Physico-Chemical Biology, Lomonosov Moscow State University, Moscow, Russia,

During their evolution, viruses acquired genes encoding movement protein(s) (MPs) that mediate the intracellular transport of viral genetic material to plasmodesmata $(\mathrm{Pd})$ and initiate the mechanisms leading to the increase in plasmodesmal permeability. Although the current view on the role of the viral MPs was primarily formed through studies on tobacco mosaic virus (TMV), the function of its MP has not been fully elucidated. Given the intercellular movement of MPs independent of genomic viral RNA (vRNA), this characteristic may induce favorable conditions ahead of the infection front for the accelerated movement of the vRNA (i.e. the MP plays a role as a "conditioner" of viral intercellular spread). This idea is supported by (a) the synthesis of MP from genomic vRNA early in infection, (b) the Pd opening and the MP transfer to neighboring cells without formation of the viral replication complex (VRC), and (c) the MP-mediated movement of VRCs beyond the primary infected cell. Here, we will consider findings that favor the TMV MP as a "conditioner" of enhanced intercellular virus movement. In addition, we will discuss the mechanism by which TMV MP opens Pd for extraordinary transport of macromolecules. Although there is no evidence showing direct effects of TMV MP on Pd leading to their dilatation, recent findings indicate that MPs exert their influence indirectly by modulating $\mathrm{Pd}$ external and structural macromolecules such as callose and Pdassociated proteins. In explaining this phenomenon, we will propose a mechanism for TMV MP functioning as a conditioner for virus movement.

Keywords: tobamovirus movement protein, tobacco mosaic virus, plasmodesmata gating, plasmodesmataassociated proteins, plasmodesmal localization signal, $\beta$-1,3-glucanase, pectin methylesterase, synaptotagmin $A$

\section{INTRODUCTION}

Since viral molecules are too large for passive transport through plasmodesmata (Pd) by diffusion, viral genomes during evolution acquired genes encoding specific proteins that can induce plasmodesmal dilation. This phenomenon was first described through fundamental studies using tobacco mosaic virus (TMV), the first discovered filtrate infectious agent (Ivanowski, 1892; Beijerinck, 1898; Lechevalier, 1972; 
Komarova et al., 2011; Dorokhov et al., 2018b). TMV spread through the plant begins with penetration into a single cell of the leaf, followed by virion stripping and the synthesis of nonstructural viral proteins in the cell (Wu et al., 1994; Wu and Shaw, 1996; Nelson and van Bel, 1998). This step is necessary for the formation of the nucleoprotein progeny that move within the cell to the Pd and then through the Pd to the neighboring cells (Waigmann et al., 2004; Niehl and Heinlein, 2011; Ueki and Citovsky, 2011). Successful systemic infection of a plant with TMV requires three processes that repeat over time: initial accumulation and formation of transport form in invaded cells, intercellular movement, and systemic transport (Waigmann et al., 2004; Liu and Nelson, 2013; Heinlein, 2015; Ishibashi and Ishikawa, 2016; Dorokhov et al., 2018b). Biologically, the movement of viruses from cell to cell is a prelude to the massive systemic invasion of the entire host plant, which begins when the viral material reaches the vascular system of the host. TMV evolutionarily acquired the ability to quickly reach the phloem for its movement into the upper sink leaves or to roots, dependent on leaf position (Samuel, 1934; Cheng et al., 2000; Liu and Nelson, 2013). A contemporary view of intercellular transport of viruses grew from the concept of a viral "transport protein" (Atabekov and Dorokhov, 1984), "translocation protein" (Leonard and Zaitlin, 1982), or "movement protein" (MP) (Atabekov and Dorokhov, 1984; Deom et al., 1987). The hypothesis that a nonstructural TMV-encoded $30 \mathrm{kDa}$ protein can facilitate viral spread (Atabekov and Morozov, 1979) was soon confirmed by the study of and use of information from the temperature-sensitive cellto-cell movement mutant Ls1 (Leonard and Zaitlin, 1982; Taliansky et al., 1982; Deom et al., 1987; Meshi et al., 1987). Two mechanisms were initially proposed to explain the function of the MP (Atabekov and Dorokhov, 1984). In the first mechanism, Pd, originally closed to the virus, are modified by MP and become permeable to viral genetic material. Thus, the MP functions to open, or gate, $\mathrm{Pd}$. The second mechanism suggested that MP did not affect Pd but rather stimulated cellular mechanisms to overcome the resistance of plant cells to the virus and allow intercellular spread. Studies of TMV and other viruses reported the basic properties of MP, including the ability to (a) increase plasmodesmal permeability for translocation of viral complexes, (b) localize to and move through Pd, and (c) bind RNA (Tilsner et al., 2014; Waigmann et al., 2004; Ueki and Citovsky, 2014; Heinlein, 2015; Navarro et al., 2019; Reagan and Burch-Smith, 2020).

However, the mechanisms of viral MP function have not been fully elucidated. Of particular interest is the selfmovement property of TMV MP. MP can move into Pd, increase their size exclusion limit (SEL) (i.e. gate $\mathrm{Pd}$ ), and travel to neighboring cells (Crawford and Zambryski, 2001; Kotlizky et al., 2001; Burch-Smith and Zambryski, 2010). Also, in accordance with the diffusion model of cell-to-cell spread (Guenoune-Gelbart et al., 2008; Epel, 2009), TMV MP forms a large complex that binds both the ER and viral RNA and can passively diffuse through $\mathrm{Pd}$. However, additionally MP's ability to move independently from viral RNA (vRNA) can serve as the basis for the mechanism of cell conditioning and the creation of a favorable environment ahead of the infection front for the accelerated movement of genomic vRNA (Kawakami et al., 2004).

Here, we assess findings that support the concept that the MP creates a conducive environment for viral infection by conditioning cells for infection in advance of the viral genomic RNA.

\section{MP IS TRANSIENTLY SYNTHESIZED IN THE EARLY STAGES OF A PRODUCTIVE INFECTION}

TMV moves rapidly between cells, needing 16-18 h (NilssonTillgren et al., 1969) to reach the vascular tissue for systemic infection of the host. Particular viral proteins should therefore be synthesized rapidly to provide this spread and the MP would be such a candidate. In support of this view, one can cite the results of experiments obtained more than 20 years ago that describe the spread of infection of TMV expressing a fusion protein MPGFP. Even as MP-GFP fusion protein, the MP retained its independent movement and contributed to the development and expansion of infection, including the necrosis phenotype, by the TMV encoding MP-GFP (Heinlein et al., 1995; Epel et al., 1996; Oparka et al., 1996; Padgett et al., 1996; Boyko et al., 2000). The TMV-based vectors used in these experiments differed significantly in the amount of MP produced, as was shown in protoplasts (Szécsi et al., 1999). However, the size of the infection focus was independent of the amount of synthesized MP-GFP. This finding indicated that low and transient levels of MP-GFP were essential at the leading edge of an expanding focus of infection. Indeed, in support of the latter assumption, TMV MPGFP could open Pd only at the leading edge of a focus of infection and did not show this ability at the later stages of infection at the focus center even though MP-GFP was still present in those Pd (Oparka et al., 1997).

Experiments studying the growing edge of the infection focus are also interesting because the behavior of MP-GFP was different from the behavior of the recombinant MP produced in E. coli, which appeared in cells distant from the injected cell after microinjection (Waigmann et al., 1994). Experiments in which DNA encoding MP-GFP was delivered into cells using low-pressure microprojectile bombardment without injuring the leaf (Crawford and Zambryski, 2000; Crawford and Zambryski, 2001) or MP-2xGFP-encoding plasmid delivered via agroinfiltration (Burch-Smith and Zambryski, 2010) demonstrated that TMV MP, similar to the cucumber mosaic virus 3a MP (Itaya et al., 1997) or the tomato spotted wilt virus NSm MP (Huang et al., 2020), showed autonomy from other viral factors, i.e., could independently move to neighboring cells in the absence of viral RNA, but remained relatively close to the initial cell with the introduced MP-encoding DNA. MP-GFP trafficked to an average of eight (Crawford and Zambryski, 2000) or nine (Crawford and Zambryski, 2001) cells adjacent to the bombarded cell. However, the distance of such movement from the 
transfected cell was noticeably less than that after microinjection with E. coli-produced MP (Waigmann et al., 1994), which could be explained by the inability of bacterially synthesized MP to be phosphorylated (Padgett et al., 1996). If we imagine that in the leading edge of expanding TMV infection sites the synthesized MP-GFP moves independently of the viral RNA into neighboring cells, the introduction of incisions as close as $50 \mu \mathrm{m}$, i.e., within one epidermal cell diameter (as was performed in the study by Oparka et al., 1997), could accidentally cut off cells already containing MPGFP that were not fluorescent yet at the time of surgery because immature GFP needs time for proper folding of the fluorophore (Cubitt et al., 1995). The absence of visible fluorescence on the opposite side of the incision $24 \mathrm{~h}$ after the incision could be due to the "dissolution" of MP-GFP, i.e., the decrease in its concentration in every next cell where it moves. The same effect of the gradient reduction of the fluorescence intensity from the primary transfected cell to the second and third order of cells was observed, for example, in experiments in which a plasmid encoding MP-GFP was introduced into individual cells, and GFP fluorescence faded with the distance from the plasmid-containing cell (Burch-Smith and Zambryski, 2010). Thus, although studies of the growing focus of infection (Oparka et al., 1997) did not allow authors to conclude that MP-GFP can move into cells of the growing edge of the focus ahead of viral RNA, experiments with the introduction of a leaf incision in front of the edge of the focus did not fully exclude this possibility.

Given the ability of MP to move independently from cell to cell, it can be hypothesized that MP-GFP, ahead of the front of the viral RNA spread, moves to neighboring healthy cells and creates favorable conditions for the development of infection. The idea of cell "conditioning" or "predisposing" (Kawakami et al., 2004) came from studies showing that TMV MP is produced in protoplasts within $5-8 \mathrm{~h}$ post infection (hpi) (Watanabe et al., 1984; Más and Beachy, 1999). Real-time monitoring of the spread of infection in tobacco leaves inoculated with transcripts of the TMV-based construct encoding MP-GFP (Padgett et al., 1996; Szécsi et al., 1999) showed that in epidermal cells in the vicinity of the initially infected cell, one can detect viral replication complex (VRC)like structures as early as 18-20 hpi. Then, after an additional 2$4 \mathrm{~h}, \mathrm{VRCs}$ can be detected in distant cells (tertiary cells), followed by a repeat of this process. In primary infected cells, the cycle is reduced by approximately $4 \mathrm{~h}$, and when the virus is transported between the 2 nd and 3 rd cells, it is reduced from 3.5 to $1.7 \mathrm{~h}$ (Kawakami et al., 2004). Notably, these calculations were made using a vector encoding fused MP-GFP protein, the synthesis of which is significantly suppressed due to a decrease in the "strength" of the subgenomic (sg) promoter directing MP-GFP sgRNA synthesis (Epel et al., 1996; Padgett et al., 1996; Szécsi et al., 1999).

All the above-mentioned considerations of the mechanisms of early synthesis of MP are based on its synthesis from a dicistronic intermediate length RNA-2 called sgRNA $\mathrm{I}_{2}$ (Bruening et al., 1976; Higgins et al., 1976; Beachy and Zaitlin, 1977; Goelet et al., 1982). However, another mechanism for the early synthesis of MP, in addition to subgenomic mRNA, has long been known (Skulachev et al., 1999; Dorokhov et al., 2002; Komarova et al., 2003; Dorokhov et al., 2006; Dorokhov et al., 2017). This mechanism involves the direct binding of ribosomes on the 75-nt sequence of the internal ribosome entry site (IRES) as part of the TMV U1 (IRES ${ }_{\mathrm{MP}, 75}{ }^{\mathrm{U} 1}$ ) genomic RNA (Skulachev et al., 1999). A similar element called $\operatorname{IRES}_{\mathrm{MP}, 75}{ }^{\mathrm{CR}}$ has been detected in the RNA of crucifer-infecting tobamovirus (crTMV) (Dorokhov et al., 1993; Dorokhov et al., 1994; Skulachev et al., 1999). The important role of IRES was demonstrated in the movement-deficient TMV U1-KK6 mutant lacking IRES $_{M P, 75}{ }^{\mathrm{U} 1}$ (Lehto et al., 1990). IRES ${ }_{M P, 75}{ }^{\mathrm{CR}}$ insertion restored the intercellular movement of the obtained variant, called TMV U1-K86 (Zvereva et al., 2004). These experiments indicated the fundamental possibility of MP synthesis not only from subgenomic RNA but also directly from genomic RNA (Figure 1). It would seem plausible that direct synthesis of MP from genomic RNA would likely be an even faster way to produce MP early in infection, perhaps working together with the subgenomic RNA to achieve this outcome.

\section{DOES THE PLASMODESMAL LOCALIZATION SIGNAL (PLS) DIRECT MP TO PD USING ER-MEDIATED TRAFFICKING?}

The discovery of a specific sequence that is responsible for MP targeting to $\mathrm{Pd}$ and designated the plasmodesmal localization signal (PLS) widened our understanding of MP function (Yuan et al., 2016; Yuan et al., 2017; Yuan et al., 2018; Liu et al., 2020). The TMV MP PLS is the first example of a PLS in plant virus MPs; however, its properties are similar to PLSs previously found in cellular transcription factors $\mathrm{KN} 1$ (Kim et al., 2005) and Dof (Chen et al., 2013). The TMV MP PLS resides in the N-terminal 50 amino acids (aa) (Yuan et al., 2016). The PLS alone, when fused with CFP, is delivered to $\mathrm{Pd}$, as shown by its localization in the plasma membrane in the plasmolysis test, while the whole MP is localized in the Pd cavity and remains associated with the cell wall after plasmolysis. As the PLS-CFP does not go to the Pd cavity, it cannot completely replace the function of the full MP. In support of other portions of the MP having function to target the Pd, MP lacking the PLS has other amino acids (61 to 80 and from 147 to 170) that help direct it to the Pd but in a less efficient manner and not to the next cells (Yuan et al., 2016; Liu et al., 2020). Analysis of cellular factors involved in interactions with MP PLS revealed its ability to bind plant synaptotagmin A (SYTA) (Yuan et al., 2018). SYTA is localized to the plasma membrane (PM), concentrated around Pd and recognized as a tethering factor of ER-PM contact sites (Uchiyama et al., 2014; Levy et al., 2015; Yuan et al., 2018; Ishikawa et al., 2020; Liu et al., 2020).

The results identifying the PLS and its ability to reach the Pd, possibly through interaction with SYTA, do not yet incorporate the known ER-actin network involvement in the intracellular delivery of MP to Pd. In general, the ability of MP to interact with 


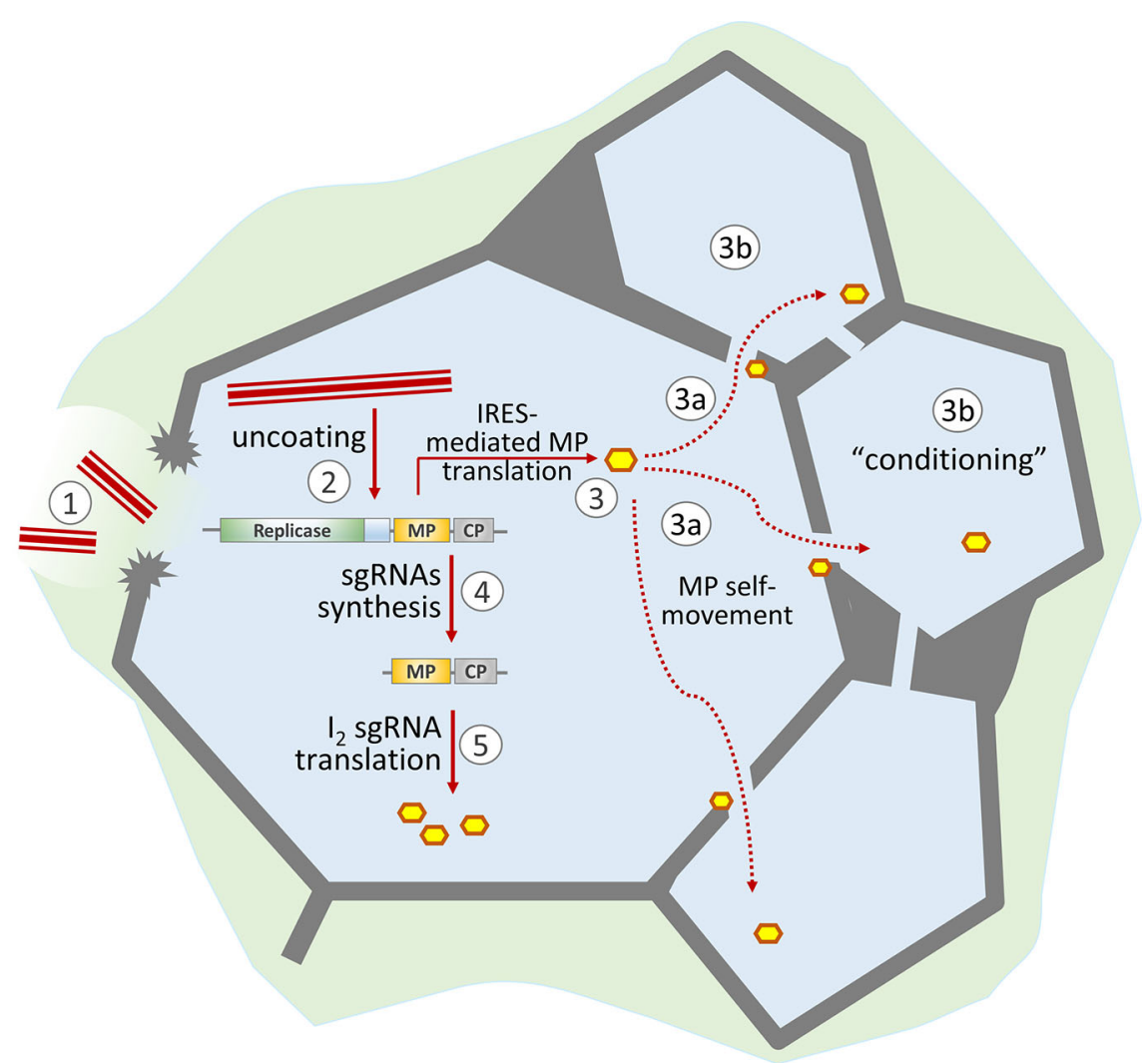

FIGURE 1 | Schematic representation of the role of MP in the development of TMV infection. TMV virions enter the cell through damage to the cell wall (1) and start uncoating (2). The released viral genomic RNA is translated both in a 5'-end-dependent manner (resulting in replicase formation) and via the internal ribosome entry site (IRES) to produce MP (3). Due to its self-movement ability, MP passes to neighboring cells (3a) and "conditions" them for more effective viral infection (3b). The synthesized replicase transcribes viral genomic RNA and produces subgenomic RNAs (4). Further MP synthesis is mainly a result of $\mathrm{I}_{2}$ sgRNA translation (5).

ER was noted more than 30 years ago, and the first studies on infected leaves showed the ability of MP synthesized in the cell to bind ER membranes so tightly that only high concentrations of $\mathrm{NaCl}$ or urea or nonionic detergents could detach it (Reichel and Beachy, 1998). It was concluded that MP behaves as an integral ER membrane protein and that the MP affinity for the ER membrane is largely hydrophobic (Reichel and Beachy, 1998). The first topological model developed after research on recombinant MP synthesized in E. coli suggested that TMV MP is an integral membrane protein with the $\mathrm{N}$ - and C-termini exposed to the cytoplasm and the opposite short loop to the ER lumen. According to that model, MP contains two $\alpha$-helical transmembrane segments, a trypsin-resistant core domain plus 18 aa at the C-terminus of the monomer rapidly removed by trypsin (Brill et al., 2000; Brill et al., 2004; Fujiki et al., 2006). However, the study of MP synthesized in planta (Peiro et al., 2014) did not confirm the above-mentioned model of MP as an integral membrane protein. According to the model proposed by Peiró et al. (2014), the hydrophilic 50-aa PLS does not interact with ER membranes. Thus, by what mechanism or mechanisms does PLS lacking the signatures of ER-interacting protein nevertheless appear in $\mathrm{Pd}$ as shown by PLS fusions with fluorescent proteins?
We hypothesize that the Golgi apparatus (GA) and cellular secretion mechanisms are involved in this process. However, opposite results have been reported. Studies with brefeldin A at low concentrations $(10 \mu \mathrm{g} / \mathrm{ml})$ (Tagami and Watanabe, 2007) and inhibition of the COP II transport system using a dominant negative GTPase mutant protein, Sar1, did not prevent sustained intracellular MP spread (Genovés et al., 2010). The recently discovered property of the TMV MP PLS to bind SYTA and the role of this interaction in delivery of the MP to the Pd requires further study. The relationship of the MP with SYTA during endosome recycling also requires further study (Lewis and Lazarowitz, 2010).

\section{POSSIBLE MECHANISMS OF CELL CONDITIONING TO FACILITATE THE INTERCELLULAR SPREAD OF INFECTION}

The TMV MP belongs to a small group of viral MPs that can increase Pd SEL; however, there is no evidence showing their direct effect on Pd components, leading to Pd dilation (Reagan and Burch-Smith, 2020). Recent data indicate that MPs exert 
their influence indirectly by interacting with factors that then influence Pd conformation, such as callose (Amsbury et al., 2017) and Pd-associated proteins (PdAPs) (Dorokhov et al., 2019). Unlike many PdAPs, callose has been convincingly shown to negatively regulate the Pd aperture (Levy et al., 2007a; Zavaliev et al., 2011; Wu et al., 2018).

One can imagine that the first synthesized MP molecules modify levels of pre-existing cellular components such as callose, which are known to control Pd gating under various physiological conditions (Crawford and Zambryski, 2001; Stonebloom et al., 2012; Grison et al., 2019) and in response to stressful effects (O'Lexy et al., 2018; Grison et al., 2019).

Studies showing how callose may be modified by other proteins and how TMV infection utilizes and/or affects the expression of these proteins have been recently reviewed (Dorokhov et al., 2019). The callose content at the Pd is largely determined by the activity of $\beta$-1,3-glucanase (BGs). In turn, TMV infection affects most BGs at the transcriptional level (Levy et al., 2007b). Therefore, while turnip vein clearing virus did not affect $A t B G \_p p a p$ transcription, the transcription of an AtBG2encoding gene was enhanced (Zavaliev et al., 2013). The introduction of the tobacco GLU I gene encoding BG into the TMV genome led to an increase in the local lesion size, which confirms the role of BG as a callose-hydrolyzing enzyme in the cell-to-cell movement of viruses (Bucher et al., 2001).

It must also be borne in mind that mechanical trauma and damage to the cell wall, which are a prerequisite for the virus to enter cells, causes the immediate release of methanol generated by both pre-existing in the cell wall pectin methylesterase (PME) and newly synthesized one (Dorokhov et al., 2012). Methanol vapors activate methanol-inducible genes (MIGs), including $B G$ and non-cell-autonomous pathway protein (NCAPP), which in turn stimulate intracellular trafficking and create favorable conditions for viral infection (Dorokhov et al., 2018a), especially at the early stages. While the synthesis of BG promotes the removal of callose as a plasmodesmal sphincter, NCAPP is a cellular factor that participates in $\mathrm{PME} / \mathrm{methanol}$ regulation (Sheshukova et al., 2017) and is indispensable for MP functioning (Lee et al., 2003; Lucas et al., 2009).

In addition to the nonspecific conditioning by the mechanisms involved in the response of a plant to trauma and the specific conditioning of cells neighboring the initially infected cell through actions on structures within or proteins that affect the Pd, the MP may influence Pd more indirectly by modulating host protein synthesis. Since MP was shown to have RNAbinding properties (Citovsky et al., 1990) and to inhibit its own

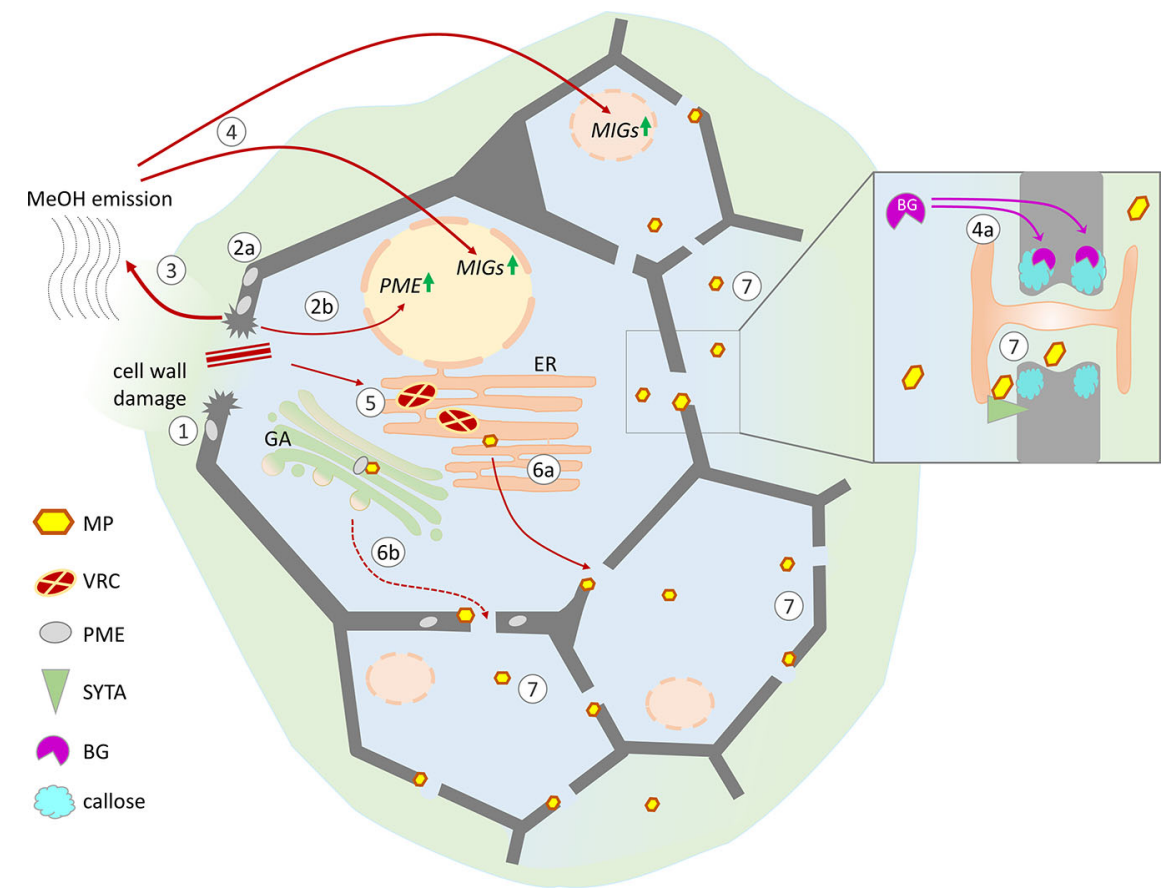

FIGURE 2 | Possible mechanisms of cell conditioning by nonviral factors induced by cell wall trauma and the specific effects of virus-directed MP, leading to the creation of favorable conditions for the intercellular spread of infection. Cell wall damage (1) results in the activation of pre-existing PME (2a) as well as PME expression (2b), leading to the increased release of gaseous methanol (3). Methanol-induced genes (MIGs), including $\beta$-1,3-glucanase (BG) and NCAPP, are stimulated by methanol (4). MIG induction activates intercellular transport increasing the Pd SEL: BG degrades callose around Pd (4a), and NCAPP is believed to be indispensable for MP functioning. TMV penetrates into the cell through damage to the cell wall, starts to replicate, and forms viral replication complexes (VRCs) on ER membranes (5). MP translated from genomic and subgenomic VRNAs is delivered to the Pd in a tight connection with ER membranes (6a) and possibly via the Golgi apparatus in a PME-mediated manner (6b). As MP colocalizes with SYTA in the VRC and Pd, the mechanisms of SYTA transport to the Pd may influence MP delivery. MP may participate in the displacement of negative regulators from the Pd structure and the activation of positive regulators (e.g., SYTA). (7) Moving independently of the genomic viral RNA to the neighboring cells MP increases Pd SEL and creates favorable conditions for the intercellular spread of infection. 
mRNA translation in vitro (Karpova et al., 1997; Karpova et al., 1999), we suggest that MP may interact with both viral and cellular mRNAs translated on ER-linked polyribosomes and participate in the inhibition of translation of messengers encoding proteins involved in the stress response and regulation of plasmodesmal permeability (Dorokhov et al., 2019; Ganusova and Burch-Smith, 2019).

Thus, against the background of events caused by cell wall damage, MP might affect Pd gating by interfering with callose metabolism and PdAPs-mediated modification of the host Pd machinery. Figure 2 summarizes the nonviral factors induced by cell wall trauma and the specific effects of virus-directed MP, leading to the creation of favorable conditions for the intercellular spread of infection.

\section{CONCLUSION}

To summarize what is known about the TMV MP, this protein is capable of

a. forming a stable vRNP complex binding single-stranded RNA in a sequence nonspecific manner;

b. targeting to and docking at Pd through the plasmodesmal localization signal;

c. self-movement and increasing Pd permeability by influencing the host Pd machinery possibly by interacting with specific cellular components that affect PdAPs or mRNA translation;

d. performing Pd gating at the leading edge of the virus infection focus.

Thus, both in a primary infected cell and in neighboring healthy cells, MP may act as a specific "conditioner", since such preliminary activity is possible only in the cells of a host plant

\section{REFERENCES}

Amsbury, S., Kirk, P., and Benitez-Alfonso, Y. (2017). Emerging models on the regulation of intercellular transport by plasmodesmata-associated callose. J. Exp. Bot. 69, 105-115. doi: 10.1093/jxb/erx337

Atabekov, J. G., and Morozov, S. Y. (1979). Translation of plant virus messenger RNAs. Adv. Virus Res. 25, 1-91. doi: 10.1016/S0065-3527(08)60568-0

Atabekov, J. G., and Dorokhov, Y. L. (1984). Plant virus-specific transport function and resistance of plants to viruses. Adv. Virus Res. 29, 313-364. doi: 10.1016/S0065-3527(08)60412-1

Beachy, R. N., and Zaitlin, M. (1977). Characterization and in vitro translation of the RNAs from less-than-full-length, virus-related, nucleoprotein rods present in tobacco mosaic virus preparations. Virology 81, 160-169. doi: 10.1016/00426822(77) $90068-\mathrm{x}$

Beijerinck, M. W. (1898). "Concerning a contagium vivum fluidum as cause of the spot disease of tobacco leaves," in Early Papers on Tobacco Mosaic and Infectious Variegation Phytopathological Classics Series (1942) (St. Paul, MN: The American Phytopathological Society), 33-52. doi: 10.1094/9780890545225.001

Boyko, V., Ferralli, J., Ashby, J., Schellenbaum, P., and Heinlein, M. (2000). Function of microtubules in intercellular transport of plant virus RNA. Nat. Cell Biol. 2, 826-832. doi: 10.1038/35041072

Brill, L. M., Nunn, R. S., Kahn, T. W., Yeager, M., and Beachy, R. N. (2000). Recombinant tobacco mosaic virus movement protein is an RNA-binding, alpha-helical membrane protein. Proc. Natl. Acad. Sci. U. S. A. 97, 7112-7117. doi: 10.1073/pnas.130187897 susceptible to TMV. Specific conditioning mechanisms may include MP interaction with BG, NCAPP, mRNA or other factors to open $\mathrm{Pd}$ in advance of vRNA.

\section{DATA AVAILABILITY STATEMENT}

The original contributions presented in the study are included in the article/supplementary material; further inquiries can be directed to the corresponding author.

\section{AUTHOR CONTRIBUTIONS}

ES, YD, TK, KK, and NE analyzed the data, drafted the outline of the manuscript, and wrote the manuscript. ES, YD, and TK revised and finalized the manuscript. All authors contributed to the article and approved the submitted version.

\section{FUNDING}

The work of YD, TK, and KK was funded by the Russian Science Foundation (project No. 19-74-20031); the work of ES and NE was supported by the Russian Foundation for Basic Research (project No. 18-34-00576).

\section{ACKNOWLEDGMENTS}

We thank the reviewers for their comments and suggestions, which have been very helpful in improving the manuscript.

Brill, L. M., Dechongkit, S., DeLaBarre, B., Stroebel, J., Beachy, R. N., and Yeager, M. (2004). Dimerization of Recombinant Tobacco Mosaic Virus Movement Protein. J. Virol. 78, 3372-3377. doi: 10.1128/JVI.78.5.3372-3377.2004

Bruening, G., Beachy, R. N., Scalla, R., and Zaitlin, M. (1976). In vitro and in vivo translation of the ribonucleic acids of a cowpea strain of tobacco mosaic virus. Virology 71, 498-517. doi: 10.1016/0042-6822(76)90377-9

Bucher, G. L., Tarina, C., Heinlein, M., Di Serio, F., Meins, F., and Iglesias, V. A. (2001). Local expression of enzymatically active class I beta-1, 3-glucanase enhances symptoms of TMV infection in tobacco. Plant J. Cell Mol. Biol. 28, 361-369. doi: 10.1046/j.1365-313x.2001.01181.x

Burch-Smith, T. M., and Zambryski, P. C. (2010). Loss of increased size exclusion limit (ISE) 1 or ISE2 increases the formation of secondary plasmodesmata. Curr. Biol. CB 20, 989-993. doi: 10.1016/j.cub.2010.03.064

Chen, H., Ahmad, M., Rim, Y., Lucas, W. J., and Kim, J.-Y. (2013). Evolutionary and molecular analysis of Dof transcription factors identified a conserved motif for intercellular protein trafficking. New Phytol. 198, 1250-1260. doi: 10.1111/nph.12223

Cheng, N. H., Su, C. L., Carter, S. A., and Nelson, R. S. (2000). Vascular invasion routes and systemic accumulation patterns of tobacco mosaic virus in Nicotiana benthamiana. Plant J. Cell Mol. Biol. 23, 349-362. doi: 10.1046/j.1365-313x.2000.00788.x

Citovsky, V., Knorr, D., Schuster, G., and Zambryski, P. (1990). The P30 movement protein of tobacco mosaic virus is a single-strand nucleic acid binding protein. Cell 60, 637-647. doi: 10.1016/0092-8674(90)90667-4

Crawford, K. M., and Zambryski, P. C. (2000). Subcellular localization determines the availability of non-targeted proteins to plasmodesmatal transport. Curr. Biol. CB 10, 1032-1040. doi: 10.1016/S0960-9822(00)00657-6 
Crawford, K. M., and Zambryski, P. C. (2001). Non-targeted and targeted protein movement through plasmodesmata in leaves in different developmental and physiological states. Plant Physiol. 125, 1802-1812. doi: 10.1104/pp.125.4.1802

Cubitt, A. B., Heim, R., Adams, S. R., Boyd, A. E., Gross, L. A., and Tsien, R. Y. (1995). Understanding, improving and using green fluorescent proteins. Trends Biochem. Sci. 20, 448-455. doi: 10.1016/s0968-0004(00)89099-4

Deom, C. M., Oliver, M. J., and Beachy, R. N. (1987). The 30-kilodalton gene product of tobacco mosaic virus potentiates virus movement. Science 237, 389394. doi: 10.1126/science.237.4813.389

Dorokhov, I. L., Ivanov, P. A., Novikov, V. K., Yefimov, V. A., and Atabekov, I. G. (1993). Tobamovirus of cruciferous plants: nucleotide sequence of genes of the transport protein, capsid protein, and 3'-terminal untranslated region. Dokl. Akad. Nauk 332, 518-522.

Dorokhov, Y. L., Ivanov, P. A., Novikov, V. K., Agranovsky, A. A., Morozov, S. Y., Efimov, V. A., et al. (1994). Complete nucleotide sequence and genome organization of a tobamovirus infecting cruciferae plants. FEBS Lett. 350, 58. doi: 10.1016/0014-5793(94)00721-7

Dorokhov, Y. L., Skulachev, M. V., Ivanov, P. A., Zvereva, S. D., Tjulkina, L. G., Merits, A., et al. (2002). Polypurine (A)-rich sequences promote crosskingdom conservation of internal ribosome entry. Proc. Natl. Acad. Sci. U. S. A. 99, 5301-5306. doi: 10.1073/pnas.082107599

Dorokhov, Y. L., Ivanov, P. A., Komarova, T. V., Skulachev, M. V., and Atabekov, J. G. (2006). An internal ribosome entry site located upstream of the cruciferinfecting tobamovirus coat protein (CP) gene can be used for CP synthesis in vivo. J. Gen. Virol. 87, 2693-2697. doi: 10.1099/vir.0.82095-0

Dorokhov, Y. L., Komarova, T. V., Petrunia, I. V., Frolova, O. Y., Pozdyshev, D. V., and Gleba, Y. Y. (2012). Airborne signals from a wounded leaf facilitate viral spreading and induce antibacterial resistance in neighboring plants. PloS Pathog. 8, e1002640. doi: 10.1371/journal.ppat.1002640

Dorokhov, Y. L., Sheshukova, E. V., and Komarova, T. V. (2017). Tobamovirus 3'Terminal Gene Overlap May be a Mechanism for within-Host Fitness Improvement. Front. Microbiol. 8, 851. doi: 10.3389/fmicb.2017.00851

Dorokhov, Y. L., Sheshukova, E. V., and Komarova, T. V. (2018a). Methanol in Plant Life. Front. Plant Sci. 9, 1623. doi: 10.3389/fpls.2018.01623

Dorokhov, Y. L., Sheshukova, E. V., and Komarova, T. V. (2018b). "Tobamoviruses and Their Diversity," in Plant Viruses: Diversity, Interaction and Management, Eds. R. K. Gaur, S. M. P. Khurana, and Y. L. Dorokhov (Boca Raton, FL: CRC Press), 65-80. doi: 10.1201/b22221-6

Dorokhov, Y. L., Ershova, N. M., Sheshukova, E. V., and Komarova, T. V. (2019). Plasmodesmata Conductivity Regulation: A Mechanistic Model. Plants Basel Switz. 8, 595. doi: 10.3390/plants8120595

Epel, B. L., Padgett, H. S., Heinlein, M., and Beachy, R. N. (1996). Plant virus movement protein dynamics probed with a GFP-protein fusion. Gene 173, 7579. doi: 10.1016/0378-1119(95)00678-8

Epel, B. L. (2009). Plant viruses spread by diffusion on ER-associated movementprotein-rafts through plasmodesmata gated by viral induced host beta-1,3glucanases. Semin. Cell Dev. Biol. 20, 1074-1081. doi: 10.1016/j.semcdb.2009.05.010

Fujiki, M., Kawakami, S., Kim, R. W., and Beachy, R. N. (2006). Domains of tobacco mosaic virus movement protein essential for its membrane association. J. Gen. Virol. 87, 2699-2707. doi: 10.1099/vir.0.81936-0

Ganusova, E. E., and Burch-Smith, T. M. (2019). Review: Plant-pathogen interactions through the plasmodesma prism. Plant Sci. Int. J. Exp. Plant Biol. 279, 70-80. doi: 10.1016/j.plantsci.2018.05.017

Genovés, A., Navarro, J. A., and Pallás, V. (2010). The Intra- and intercellular movement of Melon necrotic spot virus (MNSV) depends on an active secretory pathway. Mol. Plant-Microbe Interact. MPMI 23, 263-272. doi: 10.1094/MPMI23-3-0263

Goelet, P., Lomonossoff, G. P., Butler, P. J., Akam, M. E., Gait, M. J., and Karn, J. (1982). Nucleotide sequence of tobacco mosaic virus RNA. Proc. Natl. Acad. Sci. U. S. A. 79, 5818-5822. doi: 10.1073/pnas.79.19.5818

Grison, M. S., Kirk, P., Brault, M. L., Wu, X. N., Schulze, W. X., Benitez-Alfonso, Y., et al. (2019). Plasma Membrane-Associated Receptor-like Kinases Relocalize to Plasmodesmata in Response to Osmotic Stress. Plant Physiol. 181, 142-160. doi: 10.1104/pp.19.00473

Guenoune-Gelbart, D., Elbaum, M., Sagi, G., Levy, A., and Epel, B. L. (2008). Tobacco mosaic virus (TMV) replicase and movement protein function synergistically in facilitating TMV spread by lateral diffusion in the plasmodesmal desmotubule of Nicotiana benthamiana. Mol. Plant-Microbe Interact. MPMI 21, 335-345. doi: 10.1094/MPMI-21-3-0335

Heinlein, M., Epel, B. L., Padgett, H. S., and Beachy, R. N. (1995). Interaction of tobamovirus movement proteins with the plant cytoskeleton. Science 270, 1983-1985. doi: 10.1126/science.270.5244.1983

Heinlein, M. (2015). Plant virus replication and movement. Virology 479-480, 657-671. doi: 10.1016/j.virol.2015.01.025

Higgins, T. J., Goodwin, P. B., and Whitfeld, P. R. (1976). Occurrence of short particles in beans infected with the cowpea strain of TMV. II. Evidence that short particles contain the cistron for coat-protein. Virology 71, 486-497. doi: 10.1016/0042-6822(76)90376-7

Huang, Y., Hong, H., Xu, M., Yan, J., Dai, J., Wu, J., et al. (2020). Developmentally regulated Arabidopsis thaliana susceptibility to tomato spotted wilt virus infection. Mol. Plant Pathol. 21, 985-998. doi: 10.1111/mpp.12944

Ishibashi, K., and Ishikawa, M. (2016). Replication of Tobamovirus RNA. Аnnu. Rev. Phytopathol. 54, 55-78. doi: 10.1146/annurev-phyto-080615-100217

Ishikawa, K., Tamura, K., Fukao, Y., and Shimada, T. (2020). Structural and functional relationships between plasmodesmata and plant endoplasmic reticulum-plasma membrane contact sites consisting of three synaptotagmins. New Phytol. 226, 798-808. doi: 10.1111/nph.16391

Itaya, A., Hickman, H., Bao, Y., Nelson, R., and Ding, B. (1997). Cell-to-cell trafficking of cucumber mosaic virus movement protein:green fluorescent protein fusion produced by biolistic gene bombardment in tobacco. Plant J. 12, 1223-1230. doi: 10.1046/j.1365-313X.1997.12051223.x

Ivanowski, D. (1892). "Concerning the mosaic disease of the tobacco plant," in Early Papers on Tobacco Mosaic and Infectious Variegation Phytopathological Classics Series (1942) (St. Paul, MN: The American Phytopathological Society), 27-30. doi: 10.1094/9780890545225.001

Karpova, O. V., Ivanov, K. I., Rodionova, N. P., Dorokhov,, Yu, L., and Atabekov, J. G. (1997). Nontranslatability and dissimilar behavior in plants and protoplasts of viral RNA and movement protein complexes formed in vitro. Virology 230, 11-21. doi: 10.1006/viro.1997.8472

Karpova, O. V., Rodionova, N. P., Ivanov, K. I., Kozlovsky, S. V., Dorokhov, Y. L., and Atabekov, J. G. (1999). Phosphorylation of tobacco mosaic virus movement protein abolishes its translation repressing ability. Virology 261, 20-24. doi: 10.1006/viro.1999.9842

Kawakami, S., Watanabe, Y., and Beachy, R. N. (2004). Tobacco mosaic virus infection spreads cell to cell as intact replication complexes. Proc. Natl. Acad. Sci. U. S. A. 101, 6291-6296. doi: 10.1073/pnas.0401221101

Kim, I., Kobayashi, K., Cho, E., and Zambryski, P. C. (2005). Subdomains for transport via plasmodesmata corresponding to the apical-basal axis are established during Arabidopsis embryogenesis. Proc. Natl. Acad. Sci. U. S. A. 102, 11945-11950. doi: 10.1073/pnas.0505622102

Komarova, T. V., Skulachev, M. V., Ivanov, P. A., Klyushin, A. G., Dorokhov, Y. L., and Atabekov, J. G. (2003). Internal ribosome entry site from crucifer tobamovirus promotes initiation of translation in Escherichia coli. Dokl. Biochem. Biophys. 389, 118-121. doi: 10.1023/a:1023644408333

Komarova, T. V., Petrunia, I. V., and Dorokhov, Y. L. (2011). "Vaccine peptide display on recombinant TMV particles," in Plant-derived Vaccines: Technologies \& Applications (London, UK: Future Medicine Ltd) 44-54. doi: 10.2217/ebo.11.68

Kotlizky, G., Katz, A., van der Laak, J., Boyko, V., Lapidot, M., Beachy, R. N., et al. (2001). A dysfunctional movement protein of tobacco mosaic virus interferes with targeting of wild-type movement protein to microtubules. Mol. PlantMicrobe Interact. MPMI 14, 895-904. doi: 10.1094/MPMI.2001.14.7.895

Lechevalier, H. (1972). Dmitri Iosifovich Ivanovski, (1864-1920). Bacteriol. Rev. 36, 135-145. doi: 10.1128/MMBR.36.2.135-145.1972

Lee, J.-Y., Yoo, B.-C., Rojas, M. R., Gomez-Ospina, N., Staehelin, L. A., and Lucas, W. J. (2003). Selective trafficking of non-cell-autonomous proteins mediated by NtNCAPP1. Science 299, 392-396. doi: 10.1126/science.1077813

Lehto, K., Grantham, G. L., and Dawson, W. O. (1990). Insertion of sequences containing the coat protein subgenomic RNA promoter and leader in front of the tobacco mosaic virus $30 \mathrm{~K}$ ORF delays its expression and causes defective cell-to-cell movement. Virology 174, 145-157. doi: 10.1016/00426822(90)90063-W

Leonard, D. A., and Zaitlin, M. (1982). A temperature-sensitive strain of tobacco mosaic virus defective in cell-to-cell movement generates an altered viralcoded protein. Virology 117, 416-424. doi: 10.1016/0042-6822(82)90480-9 
Levy, A., Erlanger, M., Rosenthal, M., and Epel, B. L. (2007a). A plasmodesmataassociated beta-1,3-glucanase in Arabidopsis. Plant J. Cell Mol. Biol. 49, 669682. doi: 10.1111/j.1365-313X.2006.02986.x

Levy, A., Guenoune-Gelbart, D., and Epel, B. L. (2007b). ß-1,3-Glucanases. Plant Signal. Behav. 2, 404-407. doi: 10.4161/psb.2.5.4334

Levy, A., Zheng, J. Y., and Lazarowitz, S. G. (2015). Synaptotagmin SYTA forms ER-plasma membrane junctions that are recruited to plasmodesmata for plant virus movement. Curr. Biol. CB 25, 2018-2025. doi: 10.1016/ j.cub.2015.06.015

Lewis, J. D., and Lazarowitz, S. G. (2010). Arabidopsis synaptotagmin SYTA regulates endocytosis and virus movement protein cell-to-cell transport. Proc. Natl. Acad. Sci. 107, 2491-2496. doi: 10.1073/pnas.0909080107

Liu, C., and Nelson, R. S. (2013). The cell biology of Tobacco mosaic virus replication and movement. Front. Plant Sci. 4, 12. doi: 10.3389/fpls.2013.00012

Liu, Y., Huang, C., Zeng, J., Yu, H., Li, Y., and Yuan, C. (2020). Identification of two additional plasmodesmata localization domains in the tobacco mosaic virus cell-to-cell-movement protein. Biochem. Biophys. Res. Commun. 521, 145-151. doi: 10.1016/j.bbrc.2019.10.093

Lucas, W. J., Ham, B.-K., and Kim, J.-Y. (2009). Plasmodesmata - bridging the gap between neighboring plant cells. Trends Cell Biol. 19, 495-503. doi: 10.1016/ j.tcb.2009.07.003

Más, P., and Beachy, R. N. (1999). Replication of tobacco mosaic virus on endoplasmic reticulum and role of the cytoskeleton and virus movement protein in intracellular distribution of viral RNA. J. Cell Biol. 147, 945-958. doi: $10.1083 /$ jcb.147.5.945

Meshi, T., Watanabe, Y., Saito, T., Sugimoto, A., Maeda, T., and Okada, Y. (1987). Function of the $30 \mathrm{kd}$ protein of tobacco mosaic virus: involvement in cell-tocell movement and dispensability for replication. EMBO J. 6, 2557-2563. doi: 10.1002/j.1460-2075.1987.tb02544.x

Navarro, J. A., Sanchez-Navarro, J. A., and Pallas, V. (2019). "Chapter One - Key checkpoints in the movement of plant viruses through the host," in Advances in Virus Research. Eds. M. Kielian, T. C. Mettenleiter and M. J. Roossinck (London, UK: Academic Press), 1-64. doi: 10.1016/bs.aivir.2019.05.001

Nelson, R. S., and van Bel, A. J. E. (1998). "The Mystery of Virus Trafficking Into, Through and Out of Vascular Tissue," in Progress in Botany: Genetics Cell Biology and Physiology Ecology and Vegetation Science. Progress in Botany. Eds. H.-D. Behnke, K. Esser, J. W. Kadereit, U. Lüttge and M. Runge (Berlin, Heidelberg: Springer), 476-533. doi: 10.1007/978-3-64280446-5_17

Niehl, A., and Heinlein, M. (2011). Cellular pathways for viral transport through plasmodesmata. Protoplasma 248, 75-99. doi: 10.1007/s00709-010-0246-1

Nilsson-Tillgren, T., Kolehmainen-Sevéus, L., and von Wettstein, D. (1969). Studies on the biosynthesis of TMV. I. A system approaching a synchronized virus synthesis in a tobacco leaf. Mol. Gen. Genet. MGG 104, 124-141. doi: 10.1007/bf00272793

O’Lexy, R., Kasai, K., Clark, N., Fujiwara, T., Sozzani, R., and Gallagher, K. L. (2018). Exposure to heavy metal stress triggers changes in plasmodesmatal permeability via deposition and breakdown of callose. J. Exp. Bot. 69, 37153728. doi: 10.1093/jxb/ery171

Oparka, K. J., Boevink, P., and Santa Cruz, S. (1996). Studying the movement of plant viruses using green fluorescent protein. Trends Plant Sci. 1, 412-418. doi: 10.1016/S1360-1385(96)10043-1

Oparka, K. J., Prior, D. A., Santa Cruz, S., Padgett, H. S., and Beachy, R. N. (1997). Gating of epidermal plasmodesmata is restricted to the leading edge of expanding infection sites of tobacco mosaic virus (TMV). Plant J. Cell Mol. Biol. 12, 781-789. doi: 10.1046/j.1365-313X.1997.12040781.x

Padgett, H. S., Epel, B. L., Kahn, T. W., Heinlein, M., Watanabe, Y., and Beachy, R. N. (1996). Distribution of tobamovirus movement protein in infected cells and implications for cell-to-cell spread of infection. Plant J. Cell Mol. Biol. 10, 1079-1088. doi: 10.1046/j.1365-313X.1996.10061079.x

Peiró, A., Martínez-Gil, L., Tamborero, S., Pallás, V., Sánchez-Navarro, J. A., and Mingarro, I. (2014). The Tobacco mosaic virus movement protein associates with but does not integrate into biological membranes. J. Virol. 88, 3016-3026. doi: 10.1128/JVI.03648-13

Reagan, B. C., and Burch-Smith, T. M. (2020). Viruses Reveal the Secrets of Plasmodesmal Cell Biology. Mol. Plant-Microbe Interact. 33, 26-39. doi: 10.1094/MPMI-07-19-0212-FI
Reichel, C., and Beachy, R. N. (1998). Tobacco mosaic virus infection induces severe morphological changes of the endoplasmic reticulum. Proc. Natl. Acad. Sci. U. S. A. 95, 11169-11174. doi: 10.1073/pnas.95.19.11169

Samuel, G. (1934). The Movement of Tobacco Mosaic Virus Within the Plant. Ann. Appl. Biol. 21, 90-111. doi: 10.1111/j.1744-7348.1934.tb06891.x

Sheshukova, E. V., Komarova, T. V., Pozdyshev, D. V., Ershova, N. M., Shindyapina, A. V., Tashlitsky, V. N., et al. (2017). The intergenic interplay between aldose 1-epimerase-like protein and pectin methylesterase in abiotic and biotic stress control. Front. Plant Sci. 8, 1646. doi: 10.3389/fpls.2017.01646

Skulachev, M. V., Ivanov, P. A., Karpova, O. V., Korpela, T., Rodionova, N. P., Dorokhov, Y. L., et al. (1999). Internal initiation of translation directed by the 5 '-untranslated region of the tobamovirus subgenomic RNA I(2). Virology 263, 139-154. doi: 10.1006/viro.1999.9928

Stonebloom, S., Brunkard, J. O., Cheung, A. C., Jiang, K., Feldman, L., and Zambryski, P. (2012). Redox states of plastids and mitochondria differentially regulate intercellular transport via plasmodesmata. Plant Physiol. 158, 190199. doi: $10.1104 /$ pp. 111.186130

Szécsi, J., Ding, X. S., Lim, C. O., Bendahmane, M., Cho, M. J., Nelson, R. S., et al. (1999). Development of Tobacco Mosaic Virus Infection Sites in Nicotiana benthamiana. Mol. Plant-Microbe Interactions ${ }^{\circledR}$ 12, 143-152. doi: 10.1094/ MPMI.1999.12.2.143

Tagami, Y., and Watanabe, Y. (2007). Effects of brefeldin A on the localization of Tobamovirus movement protein and cell-to-cell movement of the virus. Virology 361, 133-140. doi: 10.1016/j.virol.2006.11.008

Taliansky, M. E., Malyshenko, S. I., Pshennikova, E. S., Kaplan, I. B., Ulanova, E. F., and Atabekov, J. G. (1982). Plant virus-specific transport function. I. Virus genetic control required for systemic spread. Virology 122, 318-326. doi: 10.1016/0042-6822(82)90231-8

Tilsner, J., Taliansky, M. E., and Torrance, L. (2014). "Plant Virus Movement," in Encyclopaedia of Life Sciences (eLS) (John Wiley \& Sons, Ltd). doi: 10.1002/ 9780470015902.a0020711.pub2

Uchiyama, A., Shimada-Beltran, H., Levy, A., Zheng, J. Y., Javia, P. A., and Lazarowitz, S. G. (2014). The Arabidopsis synaptotagmin SYTA regulates the cell-to-cell movement of diverse plant viruses. Front. Plant Sci. 5, 584. doi: $10.3389 /$ fpls.2014.00584

Ueki, S., and Citovsky, V. (2011). To gate, or not to gate: regulatory mechanisms for intercellular protein transport and virus movement in plants. Mol. Plant 4, 782-793. doi: $10.1093 / \mathrm{mp} / \mathrm{ssr} 060$

Ueki, S., and Citovsky, V. (2014). Plasmodesmata-associated proteins: can we see the whole elephant? Plant Signal. Behav. 9, e27899. doi: 10.4161/psb.27899

Waigmann, E., Lucas, W. J., Citovsky, V., and Zambryski, P. (1994). Direct functional assay for tobacco mosaic virus cell-to-cell movement protein and identification of a domain involved in increasing plasmodesmal permeability. Proc. Natl. Acad. Sci. U. S. A. 91, 1433-1437. doi: 10.1073/ pnas.91.4.1433

Waigmann, E., Ueki, S., Trutnyeva, K., and Citovsky, V. (2004). The Ins and Outs of Nondestructive Cell-to-Cell and Systemic Movement of Plant Viruses. Crit. Rev. Plant Sci. 23, 195-250. doi: 10.1080/07352680490452807

Watanabe, Y., Emori, Y., Ooshika, I., Meshi, T., Ohno, T., and Okada, Y. (1984). Synthesis of TMV-specific RNAs and proteins at the early stage of infection in tobacco protoplasts: transient expression of the $30 \mathrm{~K}$ protein and its mRNA. Virology 133, 18-24. doi: 10.1016/0042-6822(84)90421-5

$\mathrm{Wu}, \mathrm{X}$., and Shaw, J. (1996). Bidirectional uncoating of the genomic RNA of a helical virus. Proc. Natl. Acad. Sci. U. S. A. 93, 2981-2984. doi: 10.1073/pnas.93.7.2981

$\mathrm{Wu}, \mathrm{X}$., Xu, Z., and Shaw, J. G. (1994). Uncoating of tobacco mosaic virus RNA in protoplasts. Virology 200, 256-262. doi: 10.1006/viro.1994.1183

Wu, S.-W., Kumar, R., Iswanto, A. B. B., and Kim, J.-Y. (2018). Callose balancing at plasmodesmata. J. Exp. Bot. 69, 5325-5339. doi: 10.1093/jxb/ery317

Yuan, C., Lazarowitz, S. G., and Citovsky, V. (2016). Identification of a Functional Plasmodesmal Localization Signal in a Plant Viral Cell-To-Cell-Movement Protein. mBio 7, e02052-e02015. doi: 10.1128/mBio.02052-15

Yuan, C., Lazarowitz, S. G., and Citovsky, V. (2017). Identification of Plasmodesmal Localization Sequences in Proteins In Planta. J. Vis. Exp. JoVE, 55301. doi: 10.3791/55301

Yuan, C., Lazarowitz, S. G., and Citovsky, V. (2018). The Plasmodesmal Localization Signal of TMV MP Is Recognized by Plant Synaptotagmin SYTA. mBio 9, e01314-e01318. doi: 10.1128/mBio.01314-18 
Zavaliev, R., Ueki, S., Epel, B. L., and Citovsky, V. (2011). Biology of callose ( $\beta-1,3-$ glucan) turnover at plasmodesmata. Protoplasma 248, 117-130. doi: 10.1007/ s00709-010-0247-0

Zavaliev, R., Levy, A., Gera, A., and Epel, B. L. (2013). Subcellular dynamics and role of Arabidopsis $\beta$-1,3-glucanases in cell-to-cell movement of tobamoviruses. Mol. Plant-Microbe Interact. MPMI 26, 1016-1030. doi: 10.1094/MPMI-03-130062-R

Zvereva, S. D., Ivanov, P. A., Skulachev, M. V., Klyushin, A. G., Dorokhov, Y. L., and Atabekov, J. G. (2004). Evidence for contribution of an internal ribosome entry site to intercellular transport of a tobamovirus. J. Gen. Virol. 85, 17391744. doi: 10.1099/vir.0.79792-0
Conflict of Interest: The authors declare that the research was conducted in the absence of any commercial or financial relationships that could be construed as a potential conflict of interest.

Copyright $\odot 2020$ Sheshukova, Ershova, Kamarova, Dorokhov and Komarova. This is an open-access article distributed under the terms of the Creative Commons Attribution License (CC BY). The use, distribution or reproduction in other forums is permitted, provided the original author(s) and the copyright owner(s) are credited and that the original publication in this journal is cited, in accordance with accepted academic practice. No use, distribution or reproduction is permitted which does not comply with these terms. 